\title{
A new organ preservation solution for static cold storage of the liver. Amniotic fluid ${ }^{1}$
}

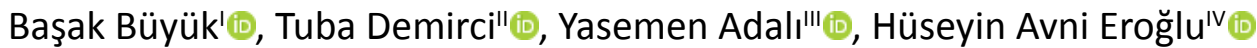

'Assistant Professor, Department of Histology-Embryology, Faculty of Medicine, Çanakkale Onsekiz Mart University, Turkey. Conception and design of the study; acquisition, analysis and interpretation of data; histopathological examinations; manuscript writing.

"Assistant Professor, Department of Histology and Embryology, Faculty of Medicine, Ataturk University, Turkey. Scientific and intellectual content of the study.

I"Assistant Professor, Department of Pathology, Faculty of Medicine, Çanakkale Onsekiz Mart University, Turkey. Histopathological examinations, statistics analysis.

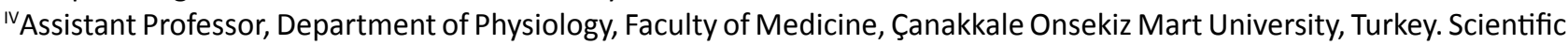
and intellectual content of the study, manuscript preparation.

\begin{abstract}
Purpose: To evaluate the effect of amniotic fluid in liver preservation in organ transplantation, and compare it with standard preservation solutions.

Methods: The groups consisted of Group 1: Ringer Lactate (RL) group, Group 2: HTK group, Group 3: UW group, Group 4: AF group. The livers of rats from Group 1, 2, 3, and 4 were perfused and placed into falcon tubes containing RL, HTK, UW, and AF solutions at $+\left.4\right|^{\circ} \mathrm{C}$, respectively. The tubes were stored for 12 hours in the refrigerator at $+4^{\circ} \mathrm{C}$. Tissue samples were taken at the $6^{\text {th }}$ and $12^{\text {th }}$ hours for histopathological examinations of the perfused livers, and storage solutions for biochemical analyzes at $6^{\text {th }}$ and $12^{\text {th }}$ hours.

Results: AF was shown to maintain organ viability by reducing the number of cells undergoing apoptosis. Histopathological changes such as sinusoidal dilatation, hydropic degeneration, and focal necrosis were found to be similar to the groups in which the standard organ preservation solutions were used. Additionally, the results of INOS, IL-10, and TNF- $\alpha$, which were evaluated immunohistochemically, have been shown to be similar to the UW and HTK groups.
\end{abstract}

Conclusions: AF provided conservation similar to UW and HTK in the 12-hour liver SCS process. The fact that apoptosis values are comparable to standard preservation solutions supports the success of AF in the cold storage of the liver.

Key words: Liver Transplantation. Amniotic Fluid. Pathology. Apoptosis. Rats. 


\section{Introduction}

Liver transplantation (LT) is a vital treatment option for patients with endstage liver failure ${ }^{1,2}$. Despite new surgical techniques, intensive care units, and recent advances in immunosuppressive therapies, a significant problem for patients waiting for transplantation is organ shortage, and the deficit between pending patients and the number of organs obtained is increasing day by day ${ }^{1,3-6}$. Since the number of organs derived from donors is limited, many patients lose their lives while waiting for an organ ${ }^{7}$. Furthermore, postoperative transplantation failure still persists, and many patients cannot survive long enough for re-transplantation due to insufficient donors ${ }^{2}$.

In addition to the shortage experienced during organ supply, keeping the viability of the organs while transfer and transplantation are crucial $^{5}$. Preservation of the liver received from the donor under ideal conditions up to the time of transplantation is the most critical step in determining whether the graft will be functional in the recipient ${ }^{2}$. This step is particularly crucial because the organs that will be transplanted in the distant centers are exposed to ischemia for a long time ${ }^{2}$.

When the organ blood flow is cut off, metabolism must be slowed down in the cell that begins to deteriorate with ischemia. The main factor in slowing cell metabolism is hypothermia ${ }^{8}$. The process that starts at this stage is static cold storage (SCS). SCS is an organ preservation method used for all organs ${ }^{5}$. In cold storage, metabolic activity is reduced by 10 times and anaerobic metabolism and lactic acidosis increase; thus, the mitochondrial energy cycle stops ${ }^{5}$. Even with the most effective preservation solutions, SCS increases graft damage before transplantation ${ }^{5}$.

Preservation solutions used in this phase help to preserve the organ without being damaged as its composition prevents the swelling of the cells ${ }^{5}$. Although many preservation solutions have been used in the last 20 years, the University of Wisconsin (UW) cold storage solution and histidinetryptophan-ketoglutarate (HTK) solutions are the most commonly used ones ${ }^{2}$. Preservation solutions contain a wide variety of substances for the prevention of cellular swelling, stabilization of the cell membrane, induction of intracellular electrolyte balance, antioxidant, and cytoprotective effects ${ }^{2}$. The UW solution developed by Belzer has been an essential invention in this field ${ }^{5}$. UW has been accepted as the gold standard in liver transplantation since $1987^{9,10}$. It has been shown that the UW solution provides protection in the donor liver, 12-18 hours in clinical trials and 48 hours in experimental studies ${ }^{3}$.

The amniotic fluid (AF) is a protective liquid that fills the amniotic cavity which surrounds the fetus in intrauterine life and is required for fetal development and maturation $^{11}$. Essentially, it protects the fetus from factors such as trauma and creates an appropriate environment for fetal growth and movement ${ }^{11} .98 \%$ of the AF content is made up of water and electrolytes; the rest is proteins, peptides, carbohydrates, lipids, amino acids, hormones, antimicrobial molecules, lactate, pyruvate, and growth factors ${ }^{12,13}$. The water in AF comes mainly from maternal plasma and reaches the amniotic cavity by passing the fetal membranes with osmotic and hydrostatic pressure ${ }^{14}$. Sodium and chloride, the primary electrolytes in the AF, are almost the same amounts as in the maternal serum. However, potassium, magnesium, calcium, and glucose are in lower concentrations than the mother serum $^{13}$.

Although most pregnant women have microorganisms in the $A F$, very few develop amniotic infections. The reason for this is that there are inhibitory substances that prevent 
the growth of microorganisms in the amniotic fluid. These substances include; lysozyme, beta lysine, transferrin, alpha defensin, peroxidase, bactericidal/permeability-increasing protein, calprotectin, a secretory leukocyte protease inhibitor, psoriasin, cathelicidin, and immunoglobulin ${ }^{11,13,14}$.

Studies have shown that as opposed to wounds in adults, fetal wounds are healed without leaving scar tissues. It was also confirmed that the rate of re-epithelisation was high in AF-treated injuries. It is claimed that the high amount of hyaluronic acid in AF may be responsible for this result ${ }^{15}$.

In another study, AF was found to increase mitosis and angiogenesis in AF-treated wounds. In this study, these effects were thought to occur due to growth factors such as fibroblast growth factor (FGF), epidermal growth factor (EGF), and transforming growth factor-beta (TGF-beta) existing in the amniotic fluid ${ }^{16}$. The amount of EGF increases in the $2^{\text {nd }}$ trimester in the human $\mathrm{AF}^{13}$. Again, TGF-alpha found in the AF plays an essential role in fetal bowel development. Also, TGF-beta is found in the AF and accelerates wound healing by stimulating cell migration. Immunoglobulin-A (Ig A) release, which is important for the immunity, also increases in the AF. Other vital substances in AF are insulin-like growth factor-1 (IGF-1), erythropoietin (EPO), and granulocyte colony-stimulating factor (G-CSF) ${ }^{13}$.

EPO is a hormone primarily secreted by the kidneys. It is responsible for regulating the number of circulating erythrocytes. In recent years, EPO receptors have been shown to be present also in the heart and brain in addition to the liver and kidneys. Thanks to these receptors, EPO acts as a cytokine, producing cytoprotective and anti-apoptotic effects, thereby preventing tissue damage ${ }^{17}$. EPO concentrations in the AF have similarities with the umbilical cord blood plasma concentration. Besides, the EPO concentrations in the $A F$ increase further during hypoxia ${ }^{18}$. EPO, which increases 2-4 times in the mother during pregnancy and enters the $A F$, plays a protective role in acute and subacute tissue damage. The cytoprotective effect is due to its antiinflammatory and anti-apoptotic properties ${ }^{19}$. Because of these protective effects, EPO has been used in some organ transplantation studies, directly ${ }^{20}$ or by adding into standard organ storage solutions ${ }^{21}$.

This study aimed to compare the use of $A F$ in organ preservation and compare it with standard preservation solutions.

\section{Methods}

This study employed an experimental design with four randomization groups. The study was approved by the Çanakkale Onsekiz Mart University (ÇOMÜ) Experimental Animal Research Ethics Committee (Approval number: 2016-02-03). Animal procedures were performed according to the "Guide for the "Care and Use of Laboratory Animals" principles ${ }^{23}$. All steps of the study were conducted at the experimental research center of the university, open for supervision.

In this study, 40 male Wistar Albino rats weighing from 220-300 g were used. The rats were supplied by the Çanakkale Onsekiz Mart University Experimental Research Center. All rats were housed in pairs in appropriate cages in an animal room maintained at a standard humidity (45\%-50\%) and temperature $\left(22 \pm 2^{\circ} \mathrm{C}\right)$ with 12 hours light and 12 hours darkness, and were fed with standard food and water ad libitum.

\section{Randomization}

The 40 male rats were randomly divided into four groups. Randomization was done by giving the rats sequential numbers and randomly assigning to groups using a randomnumbers table. 


\section{Acquisition of amniotic fluid}

AF was obtained from patients who were admitted to ÇOMÜ Obstetrics and Gynecology Clinic for term delivery, without any complications and who were not smoking, not using alcohol or any substance. AF was collected and centrifuged two times at 4000 rpm for 2 min without any time delay, and the sediment was removed each time. The supernatant obtained after centrifugation was filtered through pores of 0.22 microns.

\section{Experimental procedure}

The groups consisted of:

Group 1: Ringer Lactate (RL) group

Group 2: HTK group

Group 3: UW group

Group 4: AF group.

The surgical model used in the experiment was performed as previously described in the literature ${ }^{2,22}$. The rats were anesthetized with ketamine hydrochloride (50 $\mathrm{mg} / \mathrm{kg}$, Ketalar ${ }^{\circ}$, Pfizer, Turkey) and Xylazine (10 mg/kg, Rompun ${ }^{\circ}$, Bayer, Canada). Then a midline abdominal incision was made. After the portal vein was seen, it was entered with a cannula. Ringer Lactate (RL), HTK, and UW solutions and $A F$, which were previously stored at $+4^{\circ} \mathrm{C}$, were injected into the portal veins of rats in Group 1, 2, 3 and 4, respectively, and the liver was perfused. The hepatic vein was cut, and perfusion was continued until a clear liquid came from the vessel. Then, a hepatectomy was performed. After hepatectomy, rats were sacrificed with high dose anesthetics. The livers from Group 1, 2, 3, and 4 were placed into falcon tubes containing RL, HTK, UW, and AF solutions at $+4 \mid{ }^{b} \mathrm{C}$, respectively. The tubes were stored for 12 hours in the refrigerator at $+4{ }^{\circ} \mathrm{C}$. Tissue samples were taken at the $6^{\text {th }}$ and $12^{\text {th }}$ hours for histopathological examinations of the perfused livers. Samples were also taken from storage fluids for biochemical analyzes at $6^{\text {th }}$ and $12^{\text {th }}$ hours.

\section{Histopathological evaluation}

Tissue samples collected at the $6^{\text {th }}$ and $12^{\text {th }}$ hours after perfusion were put into $10 \%$ neutral buffered formalin without delay. At the end of the 48-hours fixation period, the tissues were subjected to routine tissue follow-up procedures. After the tissue processing protocol, livers were embedded in paraffin blocks, and sections at a thickness of \4-5 microns were obtained from the paraffin blocks with a microtome (Leica RM 2125 RTS) and stained with routine hematoxylin-eosin (H\&E) method followed by assessments with a Zeiss AxioScope A1 brand light microscope. Histopathological assessments were completed and scored for centrilobular hydropic degeneration, sinusoidal dilatation, and focal necrosis, which employ a scale ranging from 0 to 3 as follows:

$0=$ No changes found; $1=$ Mild change; 2= Moderate change; and 3= Severe change.

\section{Immunohistochemical evaluation}

Immunohistochemical (IHC) methods with TNF- $\alpha$ (Tumor necrosis factor alpha), IL-10 (Interleukin 10), and iNOS (Inducible nitric oxide synthetase) primary antibodies were used to show injury in the liver. After fixation in $10 \%$ neutral buffered formalin and routine histologic monitoring, the liver tissues embedded in paraffin blocks were sliced into 4-micron sections with a microtome and placed on adhesive slides. Antigen retrieval method was applied to the sections, which were left at $65^{\circ} \mathrm{C}$ for 1 hour and deparaffinized in xylene before passing through an alcohol series for rehydration. Later, the sections were left in 10 mM EDTA (Thermo Scientific LOT: Ax201208) for 20 minutes in a 200-watt microwave oven and then cooled at room temperature for 20 
minutes. After cooling, each slide had sections outlined with a PAP pen. Then, $3 \% \mathrm{H}_{2} \mathrm{O}_{2}$ (Thermo Scientific LOT: HP31685) was dropped onto the specimens and left on the place for 15 minutes. Later, the samples were washed in phosphate buffered saline (PBS) with a $\mathrm{pH}$ of 7.4 .

Lastly, all sections were incubated with anti-TNF- $\alpha$ (EMD Millipore Corporation, clone 13F9.1, Lot \#Q2573230), anti-IL-10(Santa Cruz Biotechnology, INC, sc-28343, Lot\#I1316), and anti-iNOS (Cell Signaling Technology, Lot\#12242) primary antibodies, marked with DAB chromogen (Thermo Scientific LOT: HA33805) and counterstained with Harris hematoxylin before being covered.

INOS staining in hepatocytes was evaluated as follows ${ }^{2}$ :

Grade 0: Less than $5 \%$ cell staining;

Grade I: $5 \%-25 \%$ cell staining;

Grade II: $25 \%-50 \%$ cell staining;

Grade III: more than $50 \%$ cell staining.

\section{Apoptosis assessment with TUNEL (Terminal} deoxynucleotidyl transferase dUTP nick end labeling) method

The terminal deoxynucleotidyl transferase dUTP nick end labeling (TUNEL) staining was used to detect apoptosis of the liver tissue. Four $\mu \mathrm{m}$ thick sections were cut from each paraffin block. After dewaxing, hydration, and serum blocking, the ApopTag Peroxidase in situ Apoptosis Detection Kit (S7100, Merck Millipore, Darmstadt, Germany) was used according to the manufacturer's protocol. In order to determine the apoptotic index (Al), five randomly selected regions of each section were chosen under $\mathrm{x} 400$ magnification. Cells stained brown or black were judged as TUNELpositive apoptotic cells. The Al of hepatocytes was determined as the percentage of TUNEL positive cells with respect to the total number of cells counted using the formula:

Apoptotic index (AI) $=$ (Number of positive cells/Total number of cells counted) x100.

\section{Blinding}

In this study, blinding was applied at the stage of the histopathological investigation. Histopathological assessments were performed by two histopathologist who had no knowledge about the groups.

\section{Biochemical evaluation}

Two $\mathrm{ml}$ samples were taken from the preservative fluid where the subjects of each group had their own liver tissue, at the $6^{\text {th }}$ and $12^{\text {th }}$ hours, to the biochemistry tubes without anticoagulant. The levels of aspartate aminotransferase (AST) and alanine aminotransferase (ALT) were measured in the biochemical laboratory using enzymatic colorimetric methods.

\section{Statistical analysis}

Data were analyzed using the SPSS Package Program version 15.0. Mean and standard deviations were used in the presentation of descriptive data. The ShapiroWilk test was used to determine the normal distribution of the variables. The Chi-Square test was used for comparing hydropic degeneration, sinusoidal dilatation, and focal necrosis degrees among the groups. One way ANOVA and the independent samples t-test were used to compare TUNEL score and ALT and AST values between the groups. The paired t-test was used for the assessment of the variables at the $6^{\text {th }}$ and $12^{\text {th }}$ hours. A $p$-value below 0.05 was considered statistically significant.

\section{Results}

The mean and standard deviations of the numerical variables are given in Table 1. 
Table 1 - Mean and standard deviations (SD) of the parametric data compared across groups.

\begin{tabular}{|c|c|c|c|c|}
\hline & $\begin{array}{c}\text { Group } 1 \\
\text { Mean } \pm S D\end{array}$ & $\begin{array}{c}\text { Group } 2 \\
\text { Mean } \pm S D\end{array}$ & $\begin{array}{c}\text { Group } 3 \\
\text { Mean } \pm S D\end{array}$ & $\begin{array}{c}\text { Group } 4 \\
\text { Mean } \pm S D\end{array}$ \\
\hline TUNEL $6^{\text {th }}$ hour & $21.9 \pm 4.4$ & $11.2 \pm 4.4$ & $10.0 \pm 3.5$ & $11.2 \pm 4.0$ \\
\hline TNF alpha $6^{\text {th }}$ hour & $1.8 \pm 0.6$ & $1.7 \pm 0.7$ & $1.8 \pm 0.6$ & $1.7 \pm 0.7$ \\
\hline IL-10 $6^{\text {th }}$ hour & $0.50 \pm 0.7$ & $1.0 \pm 0.7$ & $1.0 \pm 0.7$ & $0.9 \pm 0.7$ \\
\hline iNOS $6^{\text {th }}$ hour & $1.5 \pm 0.5$ & $1.0 \pm 0.7$ & $0.9 \pm 0.6$ & $0.9 \pm 0.6$ \\
\hline ALT $6^{\text {th }}$ & $190.8 \pm 193.0$ & $32.2 \pm 47.8$ & $160.5 \pm 83.9$ & $93.2 \pm 141.5$ \\
\hline AST $6^{\text {th }}$ & $371.5 \pm 162.1$ & $214.4 \pm 158.7$ & $366.5 \pm 219.6$ & $227.9 \pm 153.0$ \\
\hline TUNEL $12^{\text {th }}$ & $25.0 \pm 5.6$ & $14.2 \pm 5.0$ & $11.9 \pm 3.6$ & $142.0 \pm 3.8$ \\
\hline TNF alpha $12^{\text {th }}$ hour & $1.8 \pm 0.6$ & $1.7 \pm 0.8$ & $1.4 \pm 0.5$ & $1.7 \pm 0.7$ \\
\hline IL-10 $12^{\text {th }}$ hour & $0.90 \pm 0.74$ & $2.20 \pm 10.3$ & $2.10 \pm 0.74$ & $2.10 \pm 0.74$ \\
\hline iNOS $12^{\text {th }}$ hour & $2.5 \pm 1.0$ & $2.0 \pm 0.7$ & $1.8 \pm 0.8$ & $2.0 \pm 0.7$ \\
\hline ALT $12^{\text {th }}$ hour & $331.5 \pm 128.6$ & $76.4 \pm 64.2$ & $477.66 \pm 464.4$ & $259.7 \pm 261.9$ \\
\hline AST $12^{\text {th }}$ hour & $992.8 \pm 543.1$ & $540.3 \pm 528.1$ & $658.8 \pm 311.0$ & $714.3 \pm 417.8$ \\
\hline
\end{tabular}

Histopathological evaluation

Histopathological grades of all groups were placed in Table 2.

Table 2 - Grades of the histopathologic and immunohistochemical parameters belong to all groups.

\begin{tabular}{|c|c|c|c|c|c|c|c|c|c|c|c|c|c|}
\hline \multirow[t]{4}{*}{ Groups } & \multirow[t]{4}{*}{ Grades } & \multicolumn{6}{|c|}{ Immunohistochemistry } & \multicolumn{6}{|c|}{ Histopathology } \\
\hline & & \multirow{2}{*}{\multicolumn{2}{|c|}{ iNOS }} & \multicolumn{2}{|c|}{ TNF- $\alpha$} & \multicolumn{2}{|c|}{ IL-10 } & \multirow{2}{*}{\multicolumn{2}{|c|}{$\begin{array}{c}\text { Hydropic } \\
\text { degeneration } \\
\mathbf{n}\end{array}$}} & \multirow{2}{*}{\multicolumn{2}{|c|}{$\begin{array}{c}\text { Sinusoidal } \\
\text { Dilatation } \\
\mathbf{n}\end{array}$}} & \multirow{2}{*}{\multicolumn{2}{|c|}{$\begin{array}{l}\text { Focal } \\
\text { Necrosis } \\
\text { n }\end{array}$}} \\
\hline & & & & $r$ & 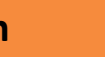 & $r$ & & & & & & & \\
\hline & & $\begin{array}{c}6^{\text {th }} \\
\text { hour }\end{array}$ & $\begin{array}{l}12^{\text {th }} \\
\text { hour }\end{array}$ & $\begin{array}{c}6^{\text {th }} \\
\text { hour }\end{array}$ & $\begin{array}{l}12^{\text {th }} \\
\text { hour }\end{array}$ & $\begin{array}{c}6^{\text {th }} \\
\text { hour }\end{array}$ & $\begin{array}{l}12^{\text {th }} \\
\text { hour }\end{array}$ & $\begin{array}{c}6^{\text {th }} \\
\text { hour }\end{array}$ & $\begin{array}{l}12^{\text {th }} \\
\text { hour }\end{array}$ & $\begin{array}{c}6^{\text {th }} \\
\text { hour }\end{array}$ & $\begin{array}{l}12^{\text {th }} \\
\text { hour }\end{array}$ & $\begin{array}{c}6^{\text {th }} \\
\text { hour }\end{array}$ & $\begin{array}{l}12^{\text {th }} \\
\text { hour }\end{array}$ \\
\hline \multirow{4}{*}{$\begin{array}{l}\text { Group } 1 \\
(n=10)\end{array}$} & 0 & 0 & 1 & 0 & 0 & 0 & 0 & 1 & 1 & 4 & 1 & 5 & 4 \\
\hline & 1 & 5 & 0 & 3 & 1 & 4 & 3 & 2 & 2 & 4 & 4 & 2 & 2 \\
\hline & 2 & 5 & 2 & 6 & 6 & 3 & 2 & 5 & 3 & 0 & 2 & 0 & 2 \\
\hline & 3 & 0 & 7 & 1 & 1 & 3 & 5 & 2 & 4 & 2 & 3 & 3 & 2 \\
\hline \multirow{4}{*}{$\begin{array}{l}\text { Group } 2 \\
(n=10)\end{array}$} & 0 & 2 & 0 & 0 & 0 & 2 & 0 & 4 & 2 & 5 & 4 & 0 & 7 \\
\hline & 1 & 6 & 2 & 4 & 5 & 6 & 5 & 4 & 4 & 4 & 5 & 8 & 2 \\
\hline & 2 & 2 & 6 & 5 & 3 & 2 & 4 & 1 & 3 & 1 & 0 & 1 & 0 \\
\hline & 3 & 0 & 2 & 1 & 2 & 0 & 1 & 1 & 1 & 0 & 1 & 1 & 1 \\
\hline \multirow{4}{*}{$\begin{array}{l}\text { Group } 3 \\
(n=10)\end{array}$} & 0 & 2 & 0 & 0 & 0 & 3 & 0 & 3 & 3 & 4 & 3 & 6 & 4 \\
\hline & 1 & 7 & 4 & 3 & 6 & 5 & 5 & 4 & 5 & 5 & 4 & 2 & 4 \\
\hline & 2 & 1 & 4 & 6 & 4 & 2 & 4 & 2 & 0 & 0 & 2 & 2 & 0 \\
\hline & 3 & 0 & 2 & 1 & 0 & 0 & 1 & 1 & 2 & 1 & 1 & 0 & 2 \\
\hline \multirow{4}{*}{$\begin{array}{l}\text { Group } 4 \\
(n=10)\end{array}$} & 0 & 2 & 0 & 0 & 0 & 3 & 0 & 4 & 2 & 4 & 7 & 6 & 4 \\
\hline & 1 & 7 & 2 & 4 & 4 & 6 & 5 & 4 & 6 & 5 & 1 & 2 & 4 \\
\hline & 2 & 1 & 6 & 5 & 5 & 1 & 4 & 1 & 0 & 1 & 1 & 2 & 1 \\
\hline & 3 & 0 & 2 & 1 & 1 & 0 & 1 & 1 & 2 & 0 & 1 & 0 & 1 \\
\hline
\end{tabular}


When the data for the sinusoidal dilatation at the $6^{\text {th }}$ hour were considered, there was no statistical significance between the groups ( $p>0.05)$. Yet, when the $12^{\text {th }}$-hour data were analyzed, a statistically significant difference was observed between the groups $(p=0.033)$. Accordingly, sinusoidal dilatation in Group 1 was significantly more than that of the Group 4. There was no statistically significant difference between the groups regarding the $6^{\text {th }}$ and $12^{\text {th }}$ hour sinusoidal dilatation $(p>$ 0.05).

There was no statistical difference between the groups in the evaluation of the
6 th and 12th hours of centrilobular hydropic degeneration and focal necrosis ( $p>0.05$ ). Similarly, there was no statistical significance in both histopathological parameters at the 6th and 12th hours of the study ( $p>0.05)$.

\section{Apoptosis evaluation with TUNEL staining}

TUNEL staining images of all groups were placed in Figure 1. When t-test was used for the independent variables of Group 1, 2, 3, and $4, \mathrm{Al}$ values examined at the $6^{\text {th }}$ and $12^{\text {th }}$ hours were significantly different in Group 1 ( $p$ values both at $6^{\text {th }}$ and $12^{\text {th }}$ hours were $<0.001$ ).
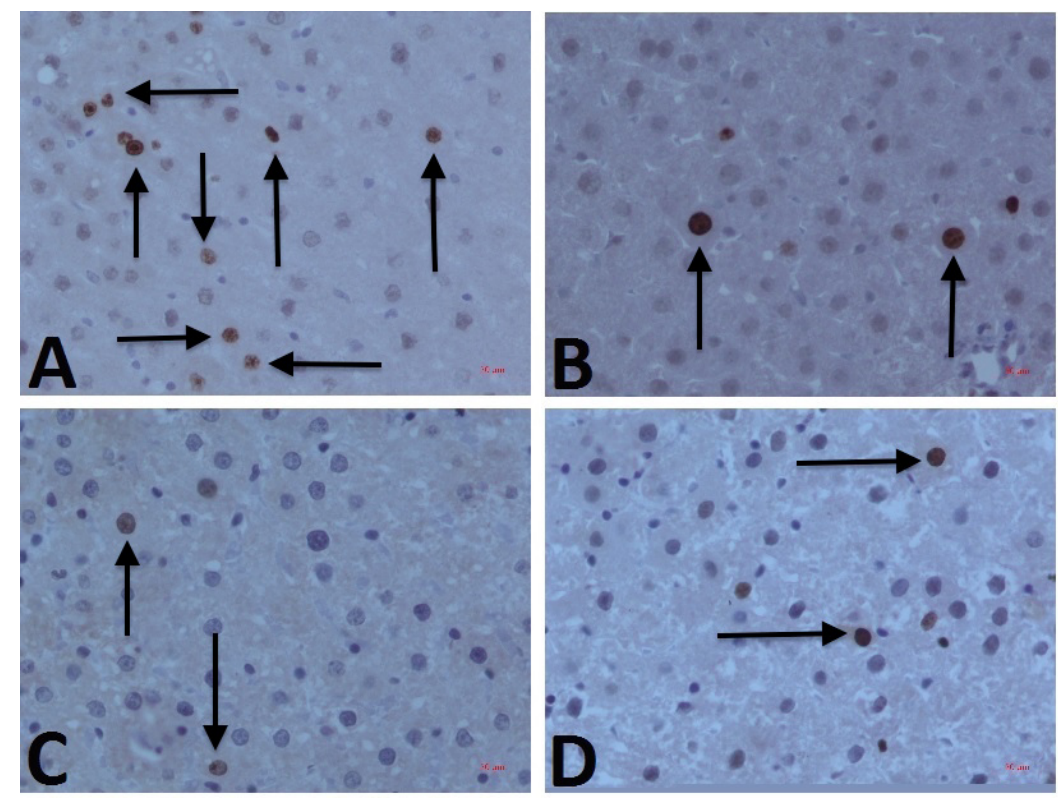

Figure 1 - TUNEL Staining images of Group 1, 2, 3 and 4 were A, B, C and D, respectively. Apoptotic cells were shown with arrows. (Magnification $\times 400$ )

There was no statistically significant difference between the Al values of Group 2 and Group 3 and 4 at the $6^{\text {th }}$ and $12^{\text {th }}$ hours ( $p$ values $0.511,1.0,0.254$, and 1.0 , respectively). When the group 3 and 4 were compared with the t-test, there was no statistically significant difference between the values of AI ( $p$ values 0.484 and 0.180 , respectively).

Compared between $6^{\text {th }}$ and $12^{\text {th }}$ hours, the $\mathrm{Al}$ levels were significantly higher in the
Group 4 only ( $p=0.025)$.

\section{Immunohistochemical evaluation}

Immunohistochemical grades of all groups were placed in Table 2 . When the iNOS immunohistochemistry was evaluated, it was found that the values at both the $6^{\text {th }}$ and the $12^{\text {th }}$ hours in Group 1 were significantly higher compared to Groups 2, 3, and 4. However, in 
the statistical analysis, only the $6^{\text {th }}$-hour data showed a significant difference between Group 1 and Group 3, in favor of the first group ( $p=$ 0.013).

When the $6^{\text {th }}$ and $12^{\text {th }}$ hour iNOS values of Group 1 were compared, it was found that the $12^{\text {th }}$-hour value was statistically higher $(p=0.032)$. No statistically significant relation was found in the comparison of the other groups at the $6^{\text {th }}$ and $12^{\text {th }}$ hours $(p>0.05)$. Similarly, there was no significant difference between the groups at the $6^{\text {th }}$ and $12^{\text {th }}$ hours of TNF- $\alpha$ and between the $6^{\text {th }}$ and $12^{\text {th }}$ hours within all groups ( $p>0.05)$.

When the $6^{\text {th }}$-hour data for IL-10 was evaluated, although the mean of the Group 1 was somewhat lower than Group 2, 3, and 4 , this difference was not statistically significant ( $p$ values $0.121,0.121$, and 0.232 , respectively). When the $12^{\text {th }}$-hour data for IL10 were examined, Group 1 had significantly lower levels than the other groups ( $p$ values for Group 2, 3 and 4 were 0.005, 0.002, and 0.002 , respectively). No statistically significant difference was found between the IL-10 values of Group 2 compared with Group 3 and $4(p=$ 0.806 for both comparisons) and also between the IL-10 values of Group 3 and Group 4 (p $=1.0)$. In the comparison of the data at the $6^{\text {th }}$ and $12^{\text {th }}$ hours, the $12^{\text {th }}$-hour data were statistically higher than the $6^{\text {th }}$-hour data in all groups ( $p$ values were $0.005,<0.001,<0.001$, and $<0.001$, respectively). Figure 2 has shown the IHC images of all groups.

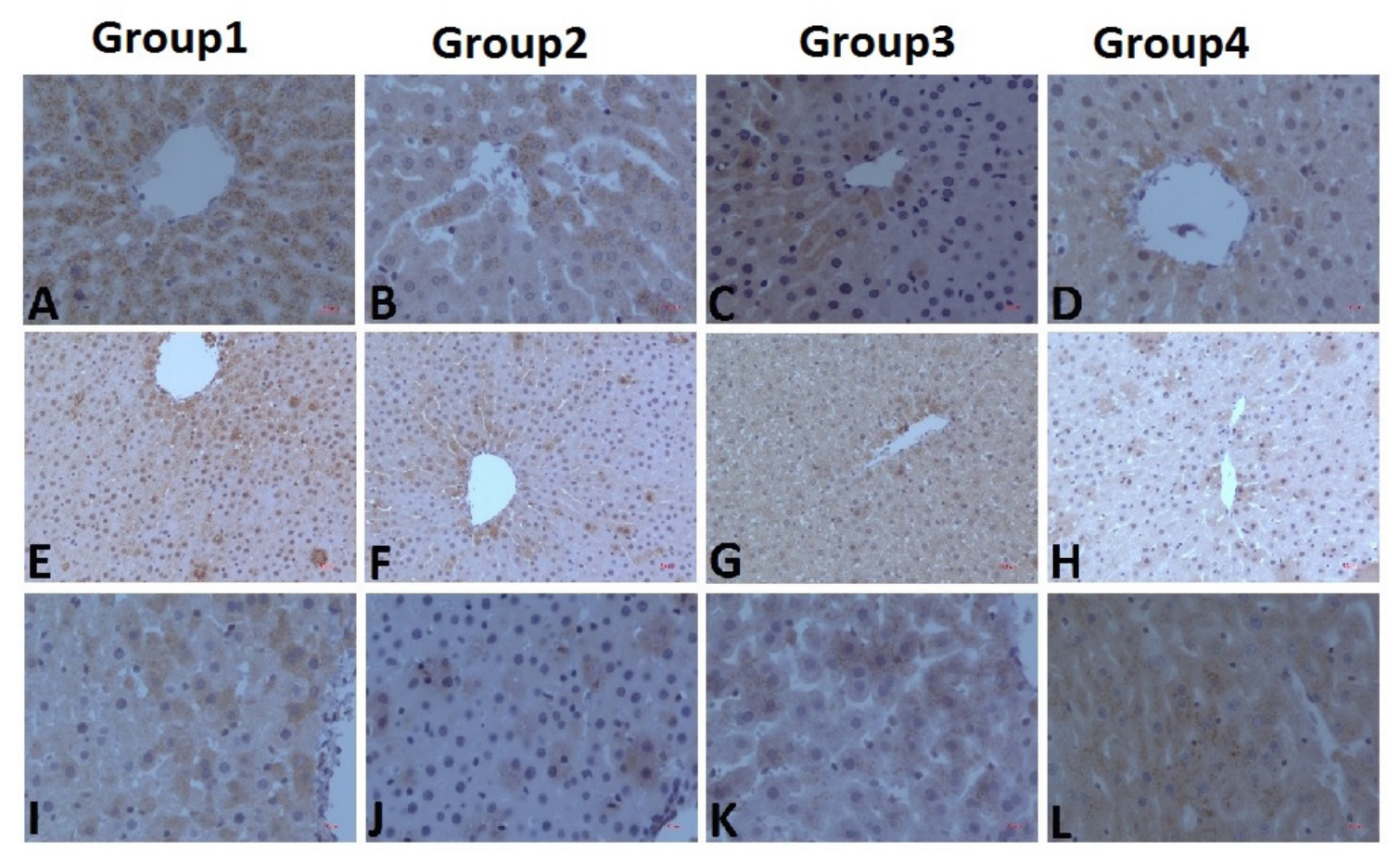

Figure 2 - IHC stainings of all groups were shown. While A, B, C and D are iNOS staining images, E, F, G and $\mathbf{H}$ are TNF- $\alpha$ and $\mathbf{I}, \mathrm{J}, \mathrm{K}$ and $\mathbf{L}$ are IL-10 staining images of groups. Magnification for $A, B, C, D, I, J, K$ and $L$ is $\times 400$, for $E, F, G$ and $H$ is $\times 200$.

Biochemical evaluation

When the $6^{\text {th }}$-hour data were evaluated for ALT, (one of the parameters we frequently use in routine practice to assess liver damage) Group 3 had significantly higher 
values compared to Group 1 and Group 2 ( $p$ values 0.030 and 0.001 , respectively). Also, the $12^{\text {th }}$-hour values were significantly higher in Group 3 compared to Group 1 and 2 ( $p$ values $<0.001$ and 0.023 , respectively). There was no statistically significant difference between the groups at the $6^{\text {th }}$ and $12^{\text {th }}$-hours $(p>0.05)$. AST values at the $6^{\text {th }}$-hour were significantly different only between Group 1 and $2(p=0.042)$.

When the mean AST were compared between the $6^{\text {th }}$ and $12^{\text {th }}$ hours within groups, $12^{\text {th }}$-hour values were significantly higher in Group 1, 2, and 3 (p values 0.010, 0.025, and $<0.001$, respectively). However, the difference was not significant for group 4 ( $p>0.05)$.

\section{Discussion}

At the end of this study, the AF was shown to protect the liver throughout the 12hour cold ischemia period in rats, comparable to standard organ preservation solutions, and maintained organ viability by reducing the number of cells undergoing apoptosis. Histopathological changes such as sinusoidal dilatation, hydropic degeneration, and focal necrosis were found to be similar to the groups in which the standard organ preservation solutions were used. Additionally, the results of INOS, IL-10, and TNF-alpha, which were evaluated immunohistochemically, have been shown to be similar to the UW and HTK groups.

The AF perfectly protects and stores the fetus during pregnancy and serves as a barrier against infections ${ }^{11-14}$; it supports the development and maturation of fetal organs throughout the intrauterine life. Studies have shown that the addition of EPO to preservation solutions during the transplantation process protects the organ from ischemia-reperfusion injury ${ }^{20,21}$. In our study, the number of apoptotic cells decreased in the AF-perfused liver tissue compared to the control group, an effect similar to using RL, UW, and HTK. Additionally, the level of sinusoidal dilatation was higher in the control group than in the AF group. This effect may be due to the protective properties of EPO in the $\mathrm{AF}$ on the liver. Besides, since the electrolytes contained are similar to the plasma levels, AF is seen as a balanced solution. Therefore, AF may have been effective in protecting and preventing damage to the cells during the SCS process.

Apoptosis is the most important parameter affecting organ viability and posttransplant success. Preserving the viability of hepatocytes enables the patient to live a healthier life after reperfusion. Standard preservation solutions have been developed to reduce hepatocyte damage and store the liver for a longer time. It was shown that UW and HTK significantly reduce the number of apoptotic cells in the liver during the SCS process compared to the control group ${ }^{2}$. In our study, apoptosis values were significantly decreased in groups using HTK, UW, and AF compared to the control group using RL. The Al values of the AF group were similar to the UW and HTK perfusion groups. This result suggests that AF may protect the liver similarly to standard solutions during cold ischemia and increase viability. We found that sinusoidal dilatation evaluated at the $12^{\text {th }}$ hour was significantly reduced in the AF group compared to the control group, which supports the success of $A F$ in liver preservation.

Nitric oxide (NO) is a potent vasodilator in the body, produced by two different nitric oxide synthases (NOS): the constitutive NOS (cNOS) and inducible NOS (iNOS). cNOS is mainly expressed in the brain (nNOS) and endothelium (eNOS), whereas iNOS is expressed in many cells in the liver, such as Kupffer cells, hepatocytes, and vascular 
smooth muscle cells ${ }^{24}$. It is known that iNOS secretion is increased during liver damage, and thus, NO produced in excess reacts with superoxide anions and forms peroxynitrite. Peroxynitrite, in turn, increases lipid damage, apoptosis, and necrosis and increases liver damage $^{25}$. In a previous study, comparing immunohistochemical iNOS values in the liver SCS model using RL, UW, and HTK perfusion, iNOS was shown to be higher in the $\mathrm{RL}$ perfusion group compared to the other groups $^{2}$. In the present study, the values of immunohistochemical iNOS were higher in the control group at the $6^{\text {th }}$ and $12^{\text {th }}$ hours compared to the other groups. The results of immunohistochemical iNOS evaluation were significantly lower in Group 4 at 6 hours, especially in patients with AF perfusion. Additionally, the results of iNOS at the $6^{\text {th }}$ and $12^{\text {th }}$ hours in Group 2 and 3 were similar to those of the AF group. This showed that AF could protect the liver from cold ischemic injury and the use of perfusion solution in transplantation surgery would have similar results with standard solutions such as UW and HTK. In the group with AF perfusion, the iNOS values were found to be significantly lower, suggesting that the amount of NO in the medium remained within the normal range, preventing the increase of lipid peroxidation and apoptosis. In our study, the $12^{\text {th }}$ hour iNOS values were significantly higher in the control group who underwent RL perfusion compared to the $6^{\text {th }}$ hour. This increase in iNOS may increase the number of cells leading to apoptosis, which may decrease organ viability and lead to a decreased post-transplantation success.

TNF- $\alpha$ is a proinflammatory cytokine synthesized from hepatocytes and Kupffer cells in the liver ${ }^{26}$. In the current study, the immunohistochemical TNF- $\alpha$ values of Group 2,3 , and 4 at the $6^{\text {th }}$ and $12^{\text {th }}$ hours were lower than the control group, but these results were not statistically significant. This may be because reperfusion was not performed in the liver during the 12 hours SCS. The release of inflammatory cytokines can increase by reperfusion, which has been evaluated in previous studies ${ }^{26,27}$. On the other hand, IL-10 is known as an anti-inflammatory cytokine. In many organs, IL-10 has been shown to reduce ischemia-reperfusion (I/R) damage and have cytoprotective effects ${ }^{26}$. The increase of IL10 in the tissue causes a decrease in many proinflammatory cytokines including TNF- $\alpha$. In this way, IL-10 can reduce hepatocyte damage in the liver ${ }^{27}$. In this study, IL-10 levels evaluated immunohistochemically were significantly higher in the UW, HTK, and AF groups compared to the control group using RL. This indicates that hepatocyte injury is reduced in these groups due to the cytoprotective effect of IL-10. In this way, the liver tissues can be protected more effectively during the SCS process. Also, the Al values were lower in these groups compared to the control group. The fact that IL-10 values are close to UW and HTK groups in the AF group and there is no statistical difference between these groups shows that in organ preservation, AF can produce similar results as standard solutions can do.

ALT and AST are the best known and widely used biochemical markers in the evaluation of hepatic damage ${ }^{28,29}$. In this study, the levels of ALT and AST measured at the $6^{\text {th }}$ and $12^{\text {th }}$ hours of organ storage in the cold ischemia process were examined. There was no significant increase in the ALT levels from 6 to 12 hours ( $p>0.05$ ). However, AST was significantly higher at the $12^{\text {th }}$ hour in Group 1,2 , and 3 ( $p$ values $0.010,0.025$, and $<0.001$, respectively). These results indicate that $A F$ is even more successful than standard solutions for the long-term SCS of the liver. 


\section{Limitations}

Successful storage of the liver in the SCS process results in a reduction in reperfusion injury. In this study, we did not reperfuse the liver in the cold ischemia model. Therefore, I/R damage assessment and post-transplant success could not be detected. Some intracellular mechanisms in the transplantation process contribute to cell damage. ATP depletion during ischemia causes loss of the transcellular electrolyte gradient, activation of free calcium influx and subsequent activation of phospholipases. Cell swelling and lysis occur as a result of all these events $^{5}$. After ischemia-reperfusion, toxic molecules are produced primarily in the form of reactive oxygen species (ROS), leading to I/R damage ${ }^{5,30}$. In our study, besides the lack of, we also did not study the oxidative stress markers. Hence, we are unable to assess the toxic effects of ROS, which is another limitation of our study.

\section{Conclusions}

Amniotic fluid provided conservation similar to UW and HTK in the 12-hour liver SCS process. The fact that apoptosis values are comparable to standard preservation solutions supports the success of AF in the cold storage of the liver.

\section{References}

1. Saidi RF. Utilization of expanded criteria donors in liver transplantation. Int J Organ Transplant Med. 2013;4(2):46. PMID: 25013654.

2. Akbulut $\mathrm{S}$, Sevmis $\mathrm{S}$, Karakayali $\mathrm{H}$, Bayraktar $\mathrm{N}$, Unlukaplan M, Oksuz E, Dagdeviren A. Amifostine enhances the antioxidant and hepatoprotective effects of UW and HTK preservation solutions. World J Gastroenter. 2014;20(34):12292. doi: 10.3748/wjg.v20. i34.12292.
3. Jia JJ, Li JH, Jiang L, Lin BY, Wang L, Su R, Zhou L, Zheng SS. Liver protection strategies in liver transplantation. Hepatobiliary Pancreat Dis Int. 2015;14(1):34-42. doi: 10.1016/S1499-3872(15)60332-0.

4. Saat TC, Susa D, Kok NF, van den Engel $S$, Roest HP, van der Laan LJ, ljzermans JNM, de Bruin RW. Inflammatory genes in rat livers from cardiac-and brain death donors. J Surg Res. 2015;198(1):217-27. doi: 10.1016/j. jss.2015.04.057.

5. Saidi RF, Kenari SKH. Liver ischemia/ reperfusion injury: an overview. J Invest Surg. 2014;27(6):366-79. doi: 10.3109/08941939.2014.932473.

6. Nishizawa $H$, Egawa $H$, Inomata $Y$, Uemoto S, Asonuma K, Kiuchi T, Yamaoka Y, Tanaka $\mathrm{K}$. Efficiency of pentoxifylline in donor pretreatment in rat liver transplantation. J Surg Res. 1997;72(2):170-6. doi: 10.1006/ jsre.1997.5169.

7. Saidi RF. Current status of liver transplantation. Arch Iran Med. 2012;15(12). doi: 0121512/AIM.0011.

8. Pienaar BH, Lindell SL, Van TG, Southard JH, Belzer FO. Seventy-two-hour preservation of the canine liver by machine perfusion. Transplantation. 1990;49(2):258-60. PMID: 2305453.

9. Panisello-Roselló A, Verde E, Lopez A, Flores $M$, Folch-Puy E, Rolo A, Palmeira C, Hotter G, Carbonell T, Adam R, Roselló-Catafau J. Cytoprotective mechanisms in fatty liver preservation against cold ischemia injury: a comparison between IGL-1 and HTK. Int J Mol Sci. 2018;19(2):348. doi: 10.3390/ ijms19020348.

10.Stewart ZA. UW solution: still the "gold standard" for liver transplantation. Am J Transplant. 2015;15(2):295-6. doi: 10.1111/ ajt.13062.

11.Defoort P. Amniotic fluid volume. International Congress Series: Elsevier; 2005. doi: 10.1016/j.ics.2004.12.033.

12.Xing-Long T, Ling W, Tan-Bing G, Yu-Guo Q, Yu-Qiao Q, Yan-Ping X. Potential function of amniotic fluid in fetal development-Novel insights by comparing the composition of human amniotic fluid with umbilical cord and maternal serum at mid and late gestation. J Chin Med Assoc. 2009;72(7):368-73. doi: 10.1016/S1726-4901(09)70389-2.

13. Underwood MA, Gilbert WM, Sherman MP. 
Amniotic fluid: not just fetal urine anymore. J Perinatol. 2005;25(5):341-8. doi: 10.1038/ sj.jp.7211290.

14.Akın A. Insan amniyon sıvısı, bu sıvının enfeksiyonuna yol açan mikroorganizmalar ve antimikrobiyal aktivitesi. Anadolu Univ J Sci Tech. 2005;6(2):137-48.

15.Nyman E, Huss F, Nyman T, Junker J, Kratz G. Hyaluronic acid, an important factor in the wound healing properties of amniotic fluid: In vitro studies of reepithelialisation in human skin wounds. J Plast Surg Hand Surg. 2013;47:89-92. doi: 10.3109/2000656X.2012.733169.

16.Bazrafshan A, Owji M, Yazdani M, Varedi $\mathrm{M}$. Activation of mitosis and angiogenesis in diabetes-impaired wound healing by processed human amniotic fluid. J Surg Res. 2014;188:545-52. doi: 10.1016/j. jss.2014.01.041.

17.Korkmaz T, Kahramansoy N, Kilicgun A, Firat $\mathrm{T}$. The effect of erythropoietin to pulmonary injury and mast cells secondary to acute pancreatitis. BMC Res Notes. 2014;7:267. doi: 10.1186/1756-0500-7-267.

18. Mikovic Z, Mandic V, Parovic V, Bogavac M, Simin N. Erythropoietin in amniotic fluid as a potential marker in distinction between growth restricted and constitutionally small fetuses. J Matern Fetal Neonatal Med. 2014;27(11):1134-7. doi: $10.3109 / 14767058.2013 .851184$.

19.Kowalska-Kańka A, Maciejewski T, Niemiec KT. The role and regulation of secretion of erythropoietin in pregnancy. Med Wieku Rozwoj. 2013;17(3):270-5. PMID: 24296452.

20.Bockhorn $M$, Fingas $C D$, Rauen $U$, Canbay A, Sotiropoulos CG, Frey U, Sheu SY, Wohlschla"ger J, Broelsch CE, Schlaak JF. Erythropoietin treatment improves liver regeneration and survival in rat models of extended liver resection and living donor liver transplantation. Transplantation. 2008;86:1578-85. doi: 10.1097/ TP.0b013e31818b22b4.

21.Schmeding M, Hunold G, Ariyakhagorn V, Rademacher $S$, Boas-Knoop S, Lippert $S$, Neuhaus P, Neumann UP. Erythropoietin reduces ischemia-reperfusion injury after liver transplantation in rats. Transplant Int. 2009;22:738-46. doi: 10.1111/j.1432- 2277.2009.00861.x.

22.Buyuk B, Karakoc E. Effects of thiopental in cold ischemia in liver transplantation: an experimental study. J Surg Med. 2019. [Epub ahead of print] doi: 10.28982/ josam.460075.

23. Committee for the Update of the Guide for the Care and Use of Laboratory Animals. Guide for the Care and Use of Laboratory Animals. 2011. doi: 10.17226/12910.

24. Meguro $M$, Katsuramaki T, Nagayama $M$, Kimura $H$, Isobe $M$, Kimura $Y$, Matsuno T, Nui A, Hirata K. A novel inhibitor of inducible nitric oxide synthase (ONO-1714) prevents critical warm ischemia-reperfusion injury in the pig liver. Transplantation. 2002;73(9):1439-46. PMID: 12023622.

25.Bektas S, Karakaya K, Can M, Bahadir B, Guven B, Erdogan N, Ozdamar SO. The effects of tadalafil and pentoxifylline on apoptosis and nitric oxide synthase in liver ischemia/reperfusion injury. Kaohsiung J Med Sci. 2016;32(7):339-47. doi: 10.1016/j. kjms.2016.05.005.

26. Qi QA, Yang ZY, Ma KS, Lu Q, Wang SG, Li XW, Xia F, Liu W, Bie P. Impact of cold ischemia on cytokines after partial liver transplantation in rats. Genet Mol Res. 2013;12(3):4003-8. doi: 10.4238/2013.September.27.1.

27.Dinant S, Veteläinen RL, Florquin S, van Vliet AK, van Gulik TM. IL-10 attenuates hepatic I/R injury and promotes hepatocyte proliferation. J Surg Res. 2007;141(2):17682. doi: 10.1016/j.jss.2006.09.018.

28. Mofrad $P$, Contos MJ, Haque M, Sargeant C, Fisher RA, Luketic VA, Sterling RK, Shiffman ML, Stravitz RT, Sanyal AJ. Clinical and histologic spectrum of nonalcoholic fatty liver disease associated with normal ALT values. Hepatology. 2003;37(6):1286-92. doi: 10.1053/jhep.2003.50229.

29.Giannini EG, Testa R, Savarino V. Liver enzyme alteration: a guide for clinicians. Can Med Assoc J. 2005;172(3):367-79. doi: 10.1503/cmaj.1040752.

30.Panisello-Roselló A, Alva N, Flores $M$, Lopez A, Castro Benítez C, Folch-Puy E, Rolo A, Palmeira C, Adam R, Carbonell T, Roselló-Catafau J. Aldehyde dehydrogenase 2 (ALDH2) in rat fatty liver cold ischemia injury. Int J Mol Sci. 2018;19(9):2479. doi: 10.3390/ijms19092479. 


\section{- Acknowledgement}

To Dr. Fatma Beyazit for collection of amniotic fluid.

\section{Correspondence}

Başak Büyük

Canakkale Onsekiz Mart University, Faculty of

Medicine

Department of Histology-Embryology

Terzioglu Campus, Canakkale Turkey

Phone: +905052372701

basakbuyuk@comu.edu.tr

Received: Dec 10, 2018

Review: Feb 13, 2019

Accepted: Mar 11, 2019
Conflict of interest: none

Financial source: The Scientific and Technological Research Council of Turkey (TÜBITAK) (Project number: 216S238)

This is an Open Access article distributed under the terms of the Creative Commons Attribution License, which permits unrestricted use, distribution, and reproduction in any medium, provided the original work is properly cited. 